\title{
An observational study of feto-maternal outcome in cases of abruptio placentae
}

\author{
Alka*, Kavita Dudhrejia \\ Department of Obstetrics and Gynecology, PDU Medical College and Hospital, Rajkot, Gujarat, India \\ Received: 25 March 2017 \\ Accepted: 27 April 2017

\section{*Correspondence:} \\ Dr. Alka, \\ E-mail: alvin27041988@gmail.com \\ Copyright: $\odot$ the author(s), publisher and licensee Medip Academy. This is an open-access article distributed under \\ the terms of the Creative Commons Attribution Non-Commercial License, which permits unrestricted non-commercial \\ use, distribution, and reproduction in any medium, provided the original work is properly cited.
}

\begin{abstract}
Background: Abruptio placentae defined as the preterm partial or complete separation of normally situated placenta from the uterine wall, complicating 1 in every 200 pregnancies (0.5-1\%) in western nations, with rates as high as $4 \%$ in developing nations.

Methods: This was a descriptive observational hospital-based study design with a follow-up component conducted over a period of 16 months, from January 2015 to April 2016 in the department of Obstetrics and Gynecology at RZH, PDU Medical College and hospital, Rajkot comprising of 83 cases.

Results: A total of 83 cases of abruption placentae were present out of 9102 deliveries at RZH, PDU Medical College, Rajkot between January 2015 to April 2016. The incidence of abruption placentae in our study is $0.9 \%$. Overall global incidence of abruptio placentae ranges between 0.5 to $2 \%$ with more in developing countries as compared to the developed nations. (1a,6a,17a). Fetal adverse outcomes of abruptio placentae observed during study period were perinatal mortality $75.9 \%$, prematurity $71 \%$, low birth weight $69.8 \%$ and asphyxia $3.6 \%$. Out of 83 cases, 59 deaths occurred in utero while 4 died in the first week of life.

Conclusions: Abruptio placentae is one of the gravest hemorrhagic complications of pregnancy. Incidence in alarmingly high in resource poor set ups of developing countries like ours. The predictors of maternal adverse outcomes were found to be malnutrition, anemia, , PPH, DIC and maternal shock. Predictors for perinatal death were low birth weight, birth asphyxia, low APGAR score, retroplacental clot volume more than $500 \mathrm{ML}$.
\end{abstract}

Keywords: Abruptio placentae, Acute renal failure, DIC, Feto-maternal outcome, PPH

\section{INTRODUCTION}

Abruptio placentae is defined as the preterm partial or complete separation of normally situated placenta from the uterine wall. It is a major cause of maternal morbidity and prenatal mortality complicating 1 in every 200 pregnancies $(0.5-1 \%)$ in western nations, however rates may be as high as $4 \%$ in developing nations. Associated perinatal mortality is as high as $25-50 \%$ with death due to abruptio placentae accounting for as much as one fourth of all perinatal mortality in some series. ${ }^{1,2}$ Though exact etiology remains obscure, various risk factors have been implicated like impaired placenation, placental insufficiency, intrauterine hypoxia, uteroplacental underperfusion hypertension, Non vertex presentation, polyhydramnios, IUGR, advanced maternal age, maternal trauma, cigarette smoking, alcohol consumption, cocaine abuse, short umbilical cord sudden decompression of uterus, retroplacental fibromyoma, post amniocentesis, prior fetal demise, previous miscarriage, grand multiparity, premature rupture of membranes, trauma and/or low pre-pregnancy body mass index. Signs and symptoms depend upon the degree of separation., 3,4

The most common presentations include vaginal bleeding, uterine and abdominal pain and tenderness, 
abnormal uterine contractions, premature labor, maternal hemodynamic instability, fetal distress and fetal death. ${ }^{5}$

Previous h/o abruption, family h/o and measurement of uterine artery flow may provide useful information. This study aims at studying the adverse feto-maternal outcomes in abruptio placentae and its predictors.

Abruptio placentae occurs in about $1 \%$ pregnancies with $0.3 \%$ in pregnancy at term throughout the world with severe abruption leading to fetal death in $0.12 \%$ of pregnancies. Incidence in India varies between 1:50 to 1:500. It may be an asymptomatic case where the diagnosis is done by the presence of a retroplacental clot post partum $(4.5 \%)$ or a classic case presenting as sudden collapse of pregnant women with either overt or covert bleeding with fetal compromise.

Objectives of present study were to Determine the incidence of abruptio placentae at department of OBS and GYN, PDU Medical College, Rajkot, determine fetomaternal outcome and determine the predictors of maternal and fetal morbidity and mortality and prolonged hospital stay in patients with Abruptio Placentae at PDU medical college, Rajkot.

\section{METHODS}

This was a descriptive observational hospital-based study design with a follow-up component. It was conducted over a period of 16 months, from January 2015 to April 2016.

The study was carried in the department of Obstetrics and Gynecology at RZH, PDU Medical College and hospital, Rajkot. This is a teaching and referral hospital with approximately 7,800 deliveries per year. The maternity unit comprises of the antenatal ward, labor ward, post natal and post LSCS ward. Mothers who need intensive care are admitted to the Obstetric ICU while babies are admitted to Neonate ICU.

Pregnant mothers diagnosed with abruptio Placenta and their babies born at RZH were included in the study. All pregnant women diagnosed to have abruption placenta from 28 weeks of gestation and above; All babies delivered by mothers with abruptio placenta at RZH were included in the study.

The study comprised of all (a total of 83) cases of abruptio placentae that came to labor ward of RZH from January 2015 to April 2016.The total no of deliveries that took place in RZH during this period were 9102.

All patients with clinical diagnosis of abruptio placenta over 28 weeks gestation characterized by painful vaginal bleeding accompanied by hypertonus uterine contractions, tender uterus \pm nonreassuring fetal heart rate/ fetal distress, fetal demise, pallor and rapid breathing with hypotension (Systolic BP $<90 \mathrm{mmHg}$ ) were recruited in the study.

\section{Study variables}

\section{Predictor variables}

Maternal variables are:

- Clinical presentations: Systolic blood pressure, Pulse rate, Vaginal bleeding and Signs of DIC

- Laboratory results: Bedside clotting time, Serum creatinine, Hemoglobin level, Prothrombin time and Platelet level

- Management received: Mode of delivery, Number of blood transfusion, Number of Fresh frozen plasma (FFP), ICU admissions, and Peripartum hysterectomy.

Fetal variables are:

- Gestation age,

- Birth weight,

- APGAR score,

- FHR,

- Mode of delivery and

- Volume of retro-placenta clot

\section{Dependent variables}

- Maternal major outcomes: Prolonged hospital stay and maternal death/survival

- Fetal major outcome: Perinatal death.

\section{Statistical analysis}

Entry and cleaning of data was done using MS Excel software. Continuous variables were grouped into categorical data then summarized as proportions and analyzed by Chi-square or Fisher's exact test. P-values of less than 0.05 were considered significant.

\section{RESULTS}

A total of 83 cases of abruption placentae were present out of 9102 deliveries at RZH, PDU Medical College, Rajkot between January 2015 to April 2016.

The incidence of abruptio placentae in this study was found to be $0.9 \%$ which is in accordance with the overall incidence of abruption placentae (1\%).

About $66.6 \%$ were in the age group of 26-35 yrs. About $56.6 \%$ were multiparous with no formal education.

$80 \%$ women were housewife by occupation. Most pregnancies culminated preterm with $39.6 \%$ between 33 to 36 weeks. 
Table 1: Baseline characteristics of participants.

\begin{tabular}{|c|c|c|c|}
\hline & Characterstic & Frequency & $\%$ \\
\hline \multirow[t]{3}{*}{$\begin{array}{l}\text { Maternal } \\
\text { age (yrs) }\end{array}$} & $=<25$ & 24 & 28.9 \\
\hline & $26-35$ & 55 & 66.2 \\
\hline & $36-45$ & 4 & 4.8 \\
\hline \multirow[t]{2}{*}{ Ooccupation } & Houswife & 68 & 81.9 \\
\hline & Peasant /farmer & 15 & 18.01 \\
\hline \multirow[t]{3}{*}{$\begin{array}{l}\text { Educational } \\
\text { level }\end{array}$} & $\begin{array}{l}\text { No formal } \\
\text { education }\end{array}$ & 47 & 56.6 \\
\hline & Primary school & 35 & 42.1 \\
\hline & $\begin{array}{l}\text { Secondary } \\
\text { school }\end{array}$ & 1 & 0.01 \\
\hline \multirow[t]{3}{*}{ Parity } & Primeparous & 24 & 28.9 \\
\hline & Multiparity (1-4) & 47 & 56.6 \\
\hline & $\begin{array}{l}\text { Grand } \\
\text { multiprity }(>4)\end{array}$ & 12 & 14.4 \\
\hline \multirow[t]{3}{*}{$\begin{array}{l}\text { Gestation } \\
\text { age (wks) }\end{array}$} & 28 to 32 & 27 & 32.5 \\
\hline & 33 to 36 & 33 & 39.7 \\
\hline & 37 to 45 & 23 & 14.4 \\
\hline \multirow[t]{2}{*}{ Hb level } & $6-10$ & 67 & 80.7 \\
\hline & $<6$ & 16 & 19.3 \\
\hline
\end{tabular}

Almost all patients were anaemic with $80.7 \%$ having a haemoglobin range of 6-10 gms and $19.3 \%$ were severely anemic with hb level below 6 gms.

Out of the various risk factors associated with abruption placentae, the ones that were found influential in this study turned out to be Multigravidity and multiparity, $45.7 \%$.

Pregnancy induced hypertension and pre-eclampsia, $14.4 \%$. Preterm premature rupture of membranes, $18.7 \%$ Low birth weight/prematurity, $34.5 \%$.

Table 2: High risk factors.

\begin{tabular}{|lll|}
\hline High risk & Frequency & $\%$ \\
\hline Prior abruption & 2 & 0.02 \\
\hline Multigravidae & 38 & 45.7 \\
\hline Pre-eclampsia & 12 & 14.4 \\
\hline Chronic hypertension & 1 & 0.01 \\
\hline Chorioamnitis & 3 & 0.03 \\
\hline Pprom & 15 & 18.7 \\
\hline Twins & 1 & 0.01 \\
\hline LBW & 29 & 34.9 \\
\hline Polyhydramnios & 1 & 0.01 \\
\hline Cigaretes/bidi & 1 & 0.01 \\
\hline Thrombophillia & 1 & 0.01 \\
\hline Cocaine abuse & - & - \\
\hline Uterus leiomyoma & - & - \\
\hline Previous CS & 4 & 0.04 \\
\hline Malpresentation & 4 & 0.04 \\
\hline
\end{tabular}

\section{High risk factors}

Among the various high risk factors associated with the occurrence of abruption placentae, the ones operative in this study at a higher rate comprised mainly of multigravidity and multiparity, pre-eclampsia and associated conditions, preterm PROM and low birh weight mostly associated with preterm deliveries.

According to the grade of abruptio placentae the distribution was given in Table 3 .

Table 3: Grade distribution.

\begin{tabular}{|lll|}
\hline Grade & No. of patients & $\%$ \\
\hline 0 & 1 & 1.2 \\
\hline I & 13 & 15.7 \\
\hline II & 11 & 13.2 \\
\hline III & 58 & 69.9 \\
\hline
\end{tabular}

\section{Maternal adverse outcomes}

Maternal mortality in this study was $7.2 \%$. $36.14 \%$ of patients had prolonged hospital stay as a result of complications that arose during the course of illness.

Table 4: Maternal adverse outcomes.

\begin{tabular}{|lll|}
\hline Outcome & Frequency & $\%$ \\
\hline Prolonged hospital stays & 30 & 36.14 \\
\hline Maternal death & 6 & 7.2 \\
\hline Acute kidney injury & 13 & 15.6 \\
\hline Icu admission & 14 & 16.8 \\
\hline $\begin{array}{l}\text { Hysterectomy } \\
\text { Need for blood } \\
\text { transfusion }\end{array}$ & 1 & 1.2 \\
\hline Anaemia & 83 & 100 \\
\hline Dic/coagulopathy & 83 & 100 \\
\hline Pph & 14 & 16.8 \\
\hline Shock & 12 & 14.4 \\
\hline
\end{tabular}

About $19.3 \%$ underwent emergency caesarean section either due to fetal distress, failed induction or those with h/o previous caesarean section. $100 \%$ patients required blood transfusion with $22.8 \%$ requiring massive transfusion (transfusion of more than 4 units of blood).

Other complications observed during the study period were anemia $(100 \%)$, primary post partum hemorrhage in $12(14.4 \%)$, coagulopathy $(16.8 \%)$, hysterectomy in one patient, acute renal failure in $13(15.6 \%)$, transfusion induced lung injury in 3 patients, shock in 11 (13.2\%) and a need for ICU care in $14(16.8 \%)$ patients.

Interestingly majority of patients with shock, early coagulopathy and early stages of renal involvement responded well to fluid challenge, furosemide and to timely blood and component therapy. 
4 required dialysis and wshifted to medicine department for same, out of which two expired due to uremic encephalopathy with poor response to dialysis.

\section{Fetal adverse outcomes}

Perinatal death in this study was $63(75.9 \%)$. Out of 59 stillbirths, 40 were fresh and 19 were old macerated stillbirths.

Out of 24 born live, 4 died within first week of life, 2 dues to extremely prematurity and low birth weight (1 and $1.3 \mathrm{kgs}), 1$ due to acute respiratory distress syndrome and other due to septicemia.

Of these $61(73.5 \%)$ were born vaginally and 2 were delivered by caesarean section.

Table 5: Fetal adverse outcomes.

\begin{tabular}{|lll|}
\hline Variables & No. of cases & $\%$ \\
\hline Live birth & 24 & 28.9 \\
\hline Fetal distress & 10 & 12.05 \\
\hline Lbw & 5 & 6.02 \\
\hline Healthy & 9 & 10.8 \\
\hline Stillborn & $59(40$, fresh 19, old $)$ & 71.08 \\
\hline
\end{tabular}

\section{Predictors of maternal survival or death}

Nine predictors were evaluated for determining maternal survival or death among pregnant women with abruption placentae.

Characteristics which were strongly associated with maternal death were:

- Coagulopathy (p value 0.00006),

- Primary post-partum hemorrhage ( $\mathrm{p}$ value 0.0005 ),

- Blood transfusion ( $\mathrm{p}$ value 0.0002),

- Component transfusion ( $\mathrm{p}$ value 0.008 ),

- Transfusion induced lung injury (0.002) and

- Acute renal failure (0.00002).

However, there was no significant association between maternal deaths and age ( $\mathrm{p}$ value 0.14$)$, shock ( $\mathrm{p}$ value 0.132 ) and anemia ( $p$ value 0.365$)$.

Maternal anemia in this study might have been caused by either acute hemorrhage, or DIC associated with abruption placentae and/or chronic anemia due to nutritional deficiency and poor antenatal care. Hence anemia can be misleading due to failure to account for its confounding factor in the study.

\section{Predictors of perinatal death}

Ten predictors were used to evaluate for the perinatal death as adverse outcomes in patients presenting with abruption placentae.
Predictors strongly associated with perinatal death were

- $\quad$ Low birth weight ( $\mathrm{p}$ value 0.002679 ),

- Gestational age ( $\mathrm{p}$ value $<0.001$ )

- Maternal anemia ( $\mathrm{p}$ value<0.001),

- Vaginal delivery ( $\mathrm{p}$ value $<0.001$ ),

- $\quad$ Low APGAR score (p value <0.001),

- Size of retroplacental clots (p value $<0.001)$ and

- $\quad$ NICU admission ( $\mathrm{p}$ value 0.01 )

Table 6: Predictors of maternal survival or death.

\begin{tabular}{|c|c|c|c|}
\hline \multirow{2}{*}{$\begin{array}{l}\text { Patients } \\
\text { characterstics }\end{array}$} & \multicolumn{2}{|c|}{ Maternal death } & \multirow[t]{2}{*}{ P-value } \\
\hline & $\begin{array}{l}\text { Yes } \\
\text { N (\%) }\end{array}$ & $\begin{array}{l}\text { No } \\
\text { N (\%) }\end{array}$ & \\
\hline \multicolumn{4}{|l|}{ Age } \\
\hline$<25$ & $3(12.5)$ & $21(87.5)$ & \multirow{3}{*}{0.14} \\
\hline $25-35$ & $2(3.6)$ & $53(96.4)$ & \\
\hline$>35$ & $1(25)$ & $3(75)$ & \\
\hline \multicolumn{4}{|l|}{ DIC } \\
\hline Yes & $5(35.7)$ & $9(64.3)$ & \multirow{2}{*}{0.00006} \\
\hline No & $1(1.4)$ & $68(98.6)$ & \\
\hline \multicolumn{4}{|l|}{ Anemia } \\
\hline$>11$ & $0(0)$ & $0(0)$ & \multirow{3}{*}{0.365} \\
\hline $6-10$ & $4(5.9)$ & $63(94.1)$ & \\
\hline$<6$ & $2(12.5)$ & $14(87.5)$ & \\
\hline \multicolumn{4}{|l|}{ Component } \\
\hline none & $0(0)$ & $42(100)$ & \multirow{3}{*}{0.008} \\
\hline $1-4$ & $0(0)$ & $11(100)$ & \\
\hline$>4$ & $6(16.6)$ & $30(95.4)$ & \\
\hline \multicolumn{4}{|l|}{ Blood } \\
\hline $\begin{array}{l}\text { None } \\
\text { transfusion }\end{array}$ & $0(0)$ & $0(0)$ & \multirow{3}{*}{0.0002} \\
\hline $1-3$ & $1(1.5)$ & $63(98.5)$ & \\
\hline$>4$ & $5(26.3)$ & $14(73.7)$ & \\
\hline \multicolumn{4}{|l|}{ Shock } \\
\hline yes & $2(18.18)$ & $9(81.8)$ & \multirow[b]{2}{*}{0.132} \\
\hline no & $4(5.5)$ & $68(94.5)$ & \\
\hline \multicolumn{4}{|l|}{ PPH } \\
\hline yes & $6(50)$ & $6(50)$ & \multirow{2}{*}{0.0005} \\
\hline no & $0(0)$ & $71(100)$ & \\
\hline \multicolumn{4}{|l|}{ ARF } \\
\hline yes & $5(38.4)$ & $8(61.6)$ & \multirow{2}{*}{0.00002} \\
\hline no & $1(1.4)$ & $69(98.6)$ & \\
\hline \multicolumn{4}{|l|}{ Trali } \\
\hline yes & $3(100)$ & $0(0)$ & \multirow[b]{2}{*}{0.002} \\
\hline no & $3(3.75)$ & $77(96.25)$ & \\
\hline
\end{tabular}

However, there was no significant association between perinatal death with maternal age, FHS on admission and sex of fetus.

\section{Predictors of prolonged hospital stay}

Out of six predictors used to evaluate /predict prolonged hospital stay in cases of abruption placentae, five were strongly associated with prolonged hospital stay 
- Postpartum hemorrhage (p value 0.046),

- Mode of delivery ( $\mathrm{p}$ value $<0.001)$,

- $\quad$ Shock (p value <0.001),

- Anemia (p value 0.008 ) and

- Acute renal failure ( $\mathrm{p}$ value $<0.001$ ).

Table 7: predictors of perinatal death.

\begin{tabular}{|c|c|c|c|}
\hline \multirow{2}{*}{$\begin{array}{l}\text { Patients } \\
\text { characterstics }\end{array}$} & \multicolumn{2}{|c|}{ Perinatal death } & \multirow[t]{2}{*}{ P-value } \\
\hline & $\begin{array}{l}\text { Yes } \\
\text { N }(\%)\end{array}$ & $\begin{array}{l}\text { No } \\
\text { N (\%) }\end{array}$ & \\
\hline \multicolumn{4}{|l|}{ Age of mother } \\
\hline$<25$ & 13 & 11 & \multirow{3}{*}{$0.0514 *$} \\
\hline $25-35$ & 47 & 8 & \\
\hline$>35$ & 3 & 1 & \\
\hline \multicolumn{4}{|l|}{ Birth weight } \\
\hline$<2.5$ & 44 & 14 & \multirow{3}{*}{$0.002679 *$} \\
\hline$>2.5-3.5$ & 16 & 9 & \\
\hline$>3.6$ & 0 & 0 & \\
\hline \multicolumn{4}{|l|}{ Gestational age } \\
\hline $28-32$ & 25 & 0 & \multirow{3}{*}{$0.000011 * *$} \\
\hline $33-36$ & 27 & 7 & \\
\hline $37-45$ & 10 & 14 & \\
\hline \multicolumn{4}{|c|}{ FHR on admission } \\
\hline F. Distress & 2 & 8 & \multirow{2}{*}{$0.7112 *$} \\
\hline $120-160$ & 2 & 12 & \\
\hline \multicolumn{4}{|l|}{ Anemia } \\
\hline$>11$ & 0 & 0 & \multirow{3}{*}{$0.0000023 *$} \\
\hline $6-10$ & 20 & 48 & \\
\hline$<5$ & 15 & 0 & \\
\hline \multicolumn{4}{|c|}{ Mode of delivery } \\
\hline VD & 61 & 12 & \multirow{2}{*}{$0.000010 * *$} \\
\hline $\mathrm{CS}$ & 2 & 8 & \\
\hline \multicolumn{4}{|l|}{ Apgar score } \\
\hline Low score & 3 & 0 & \multirow{2}{*}{$0.000034 *$} \\
\hline Normal score & 1 & 20 & \\
\hline \multicolumn{4}{|c|}{ Retroplacental clot } \\
\hline$<700$ & 20 & 54 & \multirow{2}{*}{$0.0000145^{*}$} \\
\hline$>700$ & 9 & 0 & \\
\hline \multicolumn{4}{|l|}{ Sex } \\
\hline Male & 16 & 37 & \multirow{2}{*}{$0.0845^{* *}$} \\
\hline Female & 4 & 26 & \\
\hline \multicolumn{4}{|l|}{ Admitted } \\
\hline Nicu & 4 & 2 & \multirow{2}{*}{$0.0105^{*}$} \\
\hline Not admitted & 18 & 0 & \\
\hline
\end{tabular}

\section{DISCUSSION}

Abruptio placentae remains a major cause of maternal and perinatal morbidity and mortality globally, though of more serious concern in developing world.

The incidence of abruption placentae in our study is $0.9 \%$. Overall global incidence of abruptio placentae ranges between 0.5 to $2 \%$ with more in developing countries as compared to the developed nations..$^{1-3}$
Table 8: Predictors of prolonged hospital stay.

\begin{tabular}{|c|c|c|c|}
\hline \multirow[t]{2}{*}{$\begin{array}{l}\text { Patients } \\
\text { characteristics }\end{array}$} & \multicolumn{2}{|c|}{$\begin{array}{l}\text { Prolonged hospital } \\
\text { stay }\end{array}$} & \multirow[t]{2}{*}{ P value } \\
\hline & Yes & No & \\
\hline \multicolumn{4}{|l|}{ PPH } \\
\hline Yes & 6 & 6 & \multirow{2}{*}{$0.046 * *$} \\
\hline No & 16 & 55 & \\
\hline \multicolumn{4}{|c|}{ Mode of delivery } \\
\hline VD & 12 & 55 & \multirow{2}{*}{$0.0003 * *$} \\
\hline C section & 10 & 6 & \\
\hline \multicolumn{4}{|l|}{ Shock } \\
\hline Yes & 9 & 2 & \\
\hline No & 17 & 55 & \\
\hline \multicolumn{4}{|l|}{ Anemia } \\
\hline Yes & 19 & 50 & \multirow[b]{2}{*}{$0.0001 * *$} \\
\hline No & 9 & 5 & \\
\hline \multicolumn{4}{|l|}{ Hysterectomy } \\
\hline Yes & 1 & 0 & \multirow{2}{*}{$0.265^{*}$} \\
\hline No & 21 & 61 & \\
\hline \multicolumn{4}{|l|}{ ARF } \\
\hline Yes & 8 & 5 & \multirow{2}{*}{$0.02095 *$} \\
\hline No & 20 & 50 & \\
\hline
\end{tabular}

Early detection and management of modifiable risk factors for placental abruption in developed nations might have helped to reduce the incidence of placental abruption.

Maternal adverse factors which were found prevalent in this study include maternal mortality, prolonged hospital stay, anemia, coagulopathy, hysterectomy, acute renal failure, primary postpartum hemorrhage, transfusion induced lung injury and shock.

$100 \%$ were anemic with $19.3 \%$ having severe anemia. Similar findings were evident in other studies from developing nations. ${ }^{4-6}$

A total of 83 cases of abruption placentae were present out of 9102 deliveries at RZH, PDU Medical College, Rajkot between January 2015 to April 2016 with 66.2\% of patients lying in the age group of 26-35 yrs. About $56.6 \%$ were multiparous with no formal education. $80 \%$ women were housewife by occupation. Most pregnancies culminated preterm with $39.6 \%$ between 33 to 36 weeks.

Almost all patients were anaemic with $80.7 \%$ having a haemoglobin range of 6-10 gms and $19.3 \%$ were severely anemic with hb level below 6 gms. Out of the various risk factors associated with abruption placentae, the ones that were found influential in this study turned out to be

- Multigravidity and multiparity, $45.7 \%$

- Pregnancy induced hypertension and pre-eclampsia, $14.4 \%$

- $\quad$ Preterm premature rupture of membranes, $18.7 \%$

- Low birth weight/prematurity, $34.5 \%$ 
DIC was found in 14 patients out of 83 amounting to $16.8 \%$ which was comparable to incidences of other studies ranging between 4.16 to $16.5 \% .^{7-9}$ Out of 14,5 patients were lost to DIC as they were received in the hospital in a state of irreversible shock and advanced coagulopathy. It remains one of the leading cause accounting for maternal morbidity and mortality in hemorrhagic shock if not reversed in early stages.

All patients in the study required blood transfusion depending on the amount of blood lost and whether DIC or anemia was operative. 19 patients $(22.9 \%)$ required massive transfusion and a total of $47(56.6 \%)$ required component transfusion. Out of those requiring massive transfusion, 6 expired either directly due to irreversible hypovolemic shock or indirectly due to multi organ damage resulting in acute renal failure or transfusion induced lung injury.

As majority of the patients received in our hospital were of grade III abruptio placentae $(58,69.9 \%)$, babies were stillborn and delivered vaginally. Caesarean section was taken in 10 patients (in favour of fetal distress) and 6 for failed induction/ prev cs, out of which two babies expired. The caesarean in this study turned out to be $19.2 \%$, comparable to other studies citing a range of $12.4 \%$ to $19.7 \%$. $^{3,5}$

Delivery was expedited in patients with good fetal heart sound and in whom prompt vaginal delivery was possible either by augmentation or induction keeping in account feto-maternal condition

The incidence of PPH has been reported to be between $3 \%$ and $22.2 \%$ in other studies. ${ }^{5,7,8,10}$ An incidence of $14.4 \%$ was found in this study, contributed by cases with severe anemia and coagulopathy.

Hysterectomy was performed in one patient due to intractable atonic hemorrhage, results similar to a study done by Iram et al, 2006 who reported an incidence of $1.9 \% .{ }^{10}$

Maternal shock was found in 11 patients (13.6\%) and these findings lie close to a study done by Pitaphorm et al, where shock was the leading complication in $19 \% .^{11}$

Adult intensive care admission was necessary in 14 (16.8\%) cases for close vital parameter monitoring which is high as compared to other studies reflecting a rate of 1 to $4.5 \%$ owing to late presentation to hospital with severe complications and co morbidities. ${ }^{7,12}$

Maternal mortality rate in this study was $7.2 \%$ falling in range with other studies from developing countries which have a mortality ranging from 3 to $15 \%$. $^{3,4,10,11,13}$ Developed nations face a lower maternal mortality challenge due to abruption placentae due to early attendance to hospital with fewer adverse outcomes.
The availability of fractionated clotting factors and blood products for resuscitation has improved the prognosis in our setting over the past few years. Out of 23 maternal deaths in the study period abruption accounted for 6 $(26 \%)$.

Fetal adverse outcomes of abruptio placentae observed during study period were perinatal mortality $75.9 \%$, prematurity $71 \%$, low birth weight $69.8 \%$ and asphyxia $3.6 \%$. Out of 83 cases, 59 deaths occurred in utero while 4 died in the first week of life due to severe birth asphyxia and prematurity related complications.

Although the higher perinatal death rates were comparable to most studies done in developing world, it was contrary to that reported by WHO 2009 of $15 \%$ and other developed world statistics of 9 to $12 \%$ which could be attributed to lack of comprehensive advanced care of premature babies.

Out of the 6 babies admitted at NICU, 4 expired within first week of life. All 4 were kept intubated and suffered from higher grades of hypoxia induced encephalopathy.

Interestingly in this study it was found that the prevalence of abruptio placentae was lower in mothers of female babies as compared to males $(36.14 \%$ vs $63.8 \%)$ but there was no sex difference in fetal survival observed. Gender differences associated with abruptio placentae have been reported by previous investigators.

No mother detected with abruptio placentae was managed conservatively at our institute as most had higher grades of abruption and demanded prompt intervention in favour of maternal or fetal well-being.

Generally, perinatal mortality has been strongly associated with AP across the world. In this study, the association is much stronger to low birth weight, birth asphyxia, low APGAR score, maternal anemia, preterm gestation, vaginal delivery and volume of retroplacental clots.

\section{CONCLUSION}

Abruptio placentae is one of the gravest hemorrhagic complications of pregnancy, contributing significantly to unacceptably high maternal and fetal morbidity and mortality ratios. Incidence in alarmingly high in resource poor set ups of developing countries like ours. The predictors of maternal adverse outcomes were found to be malnutrition, anemia, improper antenatal care, PPH, DIC, NICU admission and maternal shock.

Predictors for perinatal death were low birth weight, birth asphyxia, maternal anemia, low APGAR score, retroplacental clot volume more than $500 \mathrm{ML}$.

A need for mass information regarding importance of ante natal care, nutritional status and prompt diagnosis is 
envisaged. Institutional preparedness and the availability of blood and blood products in the management of abruptio placentae significantly improves fetal and maternal survival.

Funding: No funding sources

Conflict of interest: None declared

Ethical approval: The study was approved by the Institutional Ethics Committee

\section{REFERENCES}

1. Yinka Oyelese CVA. Placental Abruption. Obstet Gynecol. 2006;108:1005-16.

2. Tikkanen M. Placental abruption: epidemiology, risk factors and consequences. Acta Obstetricia et Gynecologica Scandinavica. 2011;90:140-9.

3. Hossain N. Abruptio placenta and adverse pregnancy outcome. J Pak Med Assoc. 2010;60:443-6.

4. Kizza AP. Feto-maternal haemorrhage in Kenya. East Afr Med J. 1990;67(11):801-7.

5. Ozumba BC. Abruptio placentae at the University of Nigeria Teaching Hospital, Enugu: a 3-year study. Aust N Z J Obstet Gynecol. 1989;29(2):117-20.

6. Kayani SI WS, Preston C. Pregnancy outcome in severe placental abruption. BJOG. 2003;110:679683.

7. Bibi S1, Ghaffar S, Pir MA, Yousfani S. Risk factors and clinical outcome of placental abruption. J Pak Med Assoc. 2009;59(10):672-4.
8. Jabeen M, Gul F. Abruptio placentae: risk factors and perinatal outcome. J Postgrad Med Institute (Peshawar-Pakistan). 2011;18(4).

9. Abbasi RM, Rizwan N, Mumtaz F, Farooq S. Feto maternal outcome among abruptio placentae cases at a University hospital of Sindh. JLUMHS. 2008;2:106-9.

10. Sarwar I, Abbasi Au, Islam A. Abruptio placentae and its complications at Ayub Teaching Hospital Abbottabad. J Ayub Med Coll Abbottabad. 2006;18(1):27-31.

11. Nyberg DA, Cyr DR, Mack LA, Wilson DA, Shuman WP. Sonographic spectrum of placental abruption. AJR Am J Roentgenol. 1987;148(1):1614.

12. Mmbaga BT1, Lie RT, Kibiki GS, Olomi R, Kvåle G, Daltveit AK. Transfer of newborns to neonatal care unit: a registry based study in Northern Tanzania. BMC Pregnancy Childbirth. 2011;11:68.

13. Dafallah SE, Babikir HE. Risk factors predisposing to abruptio placentae. Maternal and fetal outcome. Saudi Med J. 2004;25(9):1237-40.

Cite this article as: Alka, Dudhrejia K. An observational study of feto-maternal outcome in cases of abruptio placentae. Int J Reprod Contracept Obstet Gynecol 2017;6:3264-70. 